\title{
Gretel Adorno, Walter Benjamin, Briefwechsel
}

1930-1940

Frankfurt am Main, Suhrkamp Verlag, 2005, 433 p.

Michael Löwy

\section{(2) OpenEdition}

\section{Journals}

Édition électronique

URL : http://journals.openedition.org/assr/3836

DOI : $10.4000 /$ assr.3836

ISSN : $1777-5825$

Éditeur

Éditions de l'EHESS

Édition imprimée

Date de publication : 1 décembre 2006

Pagination : 115-283

ISBN : 2-7132-2124-2

ISSN : 0335-5985

Référence électronique

Michael Löwy, «Gretel Adorno, Walter Benjamin, Briefwechsel 1930-1940», Archives de sciences sociales des religions [En ligne], 136 | octobre - décembre 2006, document 136-3, mis en ligne le 12 février 2007, consulté le 21 septembre 2020. URL : http://journals.openedition.org/assr/3836 ; DOI : https://doi.org/ 10.4000/assr.3836

Ce document a été généré automatiquement le 21 septembre 2020.

(c) Archives de sciences sociales des religions 


\section{Gretel Adorno, Walter Benjamin, Briefwechsel 1930-1940}

Frankfurt am Main, Suhrkamp Verlag, 2005, 433 p.

\section{Michael Löwy}

1 Cet échange de correspondance entre Gretel Karplus, plus tard épouse Adorno, et Walter Benjamin, est un document émouvant sur la situation des intellectuels juifs de culture allemande dans l'entre-deux-guerres, avec ce mélange d'illusions et de lucidité qui caractérise ce groupe social.

2 W. Benjamin avait connu Gretel Karplus bien avant qu'elle ne devienne l'épouse de Theodor Wisegrund Adorno («Teddie» dans ces lettres). Sa correspondance avec celle qu'il appelait d'un tendre surnom, «Felizitas », est beaucoup plus amicale, personnelle, chaleureuse et intime que celle qu'il eut avec le philosophe. C'est ainsi que, vers 1933, ils passent, très délibérément, $d u$ "vous " au «tu ", un changement très important dans la culture sociale allemande (ce ne sera jamais le cas avec Adorno lui-même). La plupart des lettres datent des années d'exil de Benjamin en France, après la prise du pouvoir d'Hitler en 1933; soumises à la censure, elles mentionnent rarement des questions politiques. Il est évident que Gretel Adorno, restée en Allemagne jusqu'en 1937, se faisait des illusions sur la nature du nouveau régime puisqu'elle demande, encore en 1934, si Benjamin n'envisage pas de revenir en Allemagne... Mais, en même temps, elle semble se rendre compte de la précarité de la situation des juifs, puisqu'elle interroge son ami sur ce qu'il dirait si elle se convertissait au catholicisme. C'était encore une incompréhension de la dynamique du racisme du Troisième Reich, qui se moquait des confessions religieuses des juifs.

Outre les soucis de la vie quotidienne - généreuse, Gretel Karplus envoyait périodiquement des "billets roses" (envois postaux) pour aider financièrement son ami - il est surtout question dans ces lettres des travaux de Benjamin, d'abord sur Kafka, et ensuite sur Baudelaire. Comme Gershom Scholem, Gretel Adorno se méfiait de l'influence de Brecht sur son ami, qu'elle jugeait "dangereuse». La réponse de Benjamin est très intéressante et très révélatrice : «Ma vie ainsi que ma pensée est en mouvement dans des positions extrêmes. (...) La liberté de mettre réciproquement en 
mouvement des choses et des idées qui sont considérées incompatibles, ne trouve son vrai visage que par le danger ». Cette remarque permet de comprendre aussi la façon dont il va relier, dans ses derniers écrits, des idées aussi «incompatibles » que la théologie et le marxisme, le messianisme et le matérialisme historique.

Il est souvent question d'amis communs, comme Ernst Bloch ou G. Scholem, dans leurs échanges, sans parler, bien entendu, de «Teddie» Adorno. Dans une lettre de 1938, Felizitas se demande si Scholem n'est pas, au fond, un "frankiste", c'est-à-dire un partisan de l'étrange Jakob Frank, fondateur d'une branche messianique hérétique et nihiliste du sabbatianisme au sein du judaïsme polonais du xviII ${ }^{e}$ siècle, sur laquelle l'historien de Jérusalem écrivit plusieurs essais. Benjamin s'abstient de répondre...

Les dernières lettres, de 1939-40, sont les plus poignantes. «Felizitas » et "Teddie » tentent de lui envoyer des documents qui pourraient lui assurer un visa d'entrée pour les États-Unis. Trop tard... Les lettres de Benjamin, rédigées en français - «pour faciliter le travail de la censure ", écrit-il - décrivent sa situation de plus en plus précaire. Dès le début de la guerre, les « ressortissants de pays ennemis » - c'est-à-dire les juifs et les anti-fascistes allemands et autrichiens réfugiés en France! - sont enfermés par la III $^{\mathrm{e}}$ République finissante dans des camps d'internement. C'est seulement dans cette dernière période que la question de l'antisémitisme affleure dans leur correspondance: Benjamin s'interroge, à propos d'un article de son ami Max Horkheimer, «dans quelle mesure le mouvement antisémite [actuel] dépend ou bien s'oppose à l'antisémitisme moyen-âgeux ».

C'est dans une de ses dernières lettres, de mai 1940, qu'il annonce à «Felizitas » qu'il vient de rédiger, sous forme de Thèse, une synthèse de sa conception de l'histoire : « La guerre et la constellation qui l'a amenée m'ont conduit à coucher sur le papier quelques pensées, à propos desquelles je peux dire que je les garde sur moi - et même de moi depuis environ une vingtaine d'années ». Il s'agit de son testament philosophique, le document "Sur le concept d'histoire», qui revient, sous une forme nouvelle, imprégnée de marxisme, sur quelques thèmes de ses écrits théologiques de jeunesse (1915-1920). Lors de leur rencontre à Paris en 1937, il avait déjà exposé à Gretel et Theodor Adorno sa critique de l'idéologie du progrès: cette conversation «sous les marronniers ", écrit-il à Gretel, « a été une brèche dans ces vingt années ». Aujourd'hui, ajoute-t-il, je t'envoie ces pensées "plutôt comme un bouquet d'herbes bruissantes, ramassées lors de promenades pensives, que comme un recueil de thèses ".

Quelques mois plus tard, arrêté par la police à la frontière espagnole (Port-Bou) et menacé d'être livré à la Gestapo, Walter Benjamin choisit le suicide. 